\title{
Incidence of Corneal Ulcer in Dogs - A Retrospective Study
}

\author{
K. P. Patel, P. V. Parikh*, J. K. Mahla, S. N. Ashwath and D. N. Kelawala \\ Department of Surgery \& Radiology, Veterinary Collage, AAU, Anand, India \\ *Corresponding author
}

\section{A B S T R A C T}

\section{Keywords}

Corneal ulcer, Corneal melanosis, Cataract, Young age groups

Article Info

Accepted:

24 July 2020

Available Online:

10 August 2020
The retrospective data on corneal ulcer in dogs registered at Veterinary Clinical Complex, AAU, Anand from March, 2019 to February, 2020 was analysed to elicit the incidence of corneal ulcer in dogs based on the Age, Sex, Breed, Symmetry, Affected eyes, Causative factor and Location of ulcer. During the period of present study, out of total of 5129 clinical cases of dogs 220 cases of dogs were found to be affected with various ocular affections. Out of 220 cases of corneal affections, the highest cases of corneal melanosis followed by corneal ulcer and cataract were observed. The highest incidence of corneal ulcer was found in Pug followed by Pomeranian and Mongrels with the maximum cases in young age group.

\section{Introduction}

The eye is a window to the world. It's the only organ of vision at the best and a biological camera (Dutta, 2006). Due to lack of awareness among the pet owners and clinicians, the ocular problems in pet animals are getting worsen day by day (Slatter, 2001). The incidence of ocular affection was found to be high in canine in which, condition of cornea and lens are the most important, since diseases of this structure directly affect the vision (Gelatt and Katz, 2000). Corneal ulcer is one of the most common eye diseases in dogs and most common reasons of an eye to be painful along with being the most common cause of blindness in dogs, but in most of the cases it is treatable. Hence the objective of the present study was to record incidence of corneal ulcer based on the Age, Sex, Breed, Symmetry, Affected eyes, Causative factor and Location of ulcer.

In India, veterinary ophthalmology is in developing stage and remains the domain of general veterinary surgeon, therefore with few exceptions, the important field remains more or less neglected. So this study was planned to assess the magnitude of corneal ulcer in dogs. 


\section{Materials and Methods}

The study was conducted to find out the occurrence of corneal ulcer with respect to Age, Sex, Breed, Symmetry, affected eyes, Causative factor, Location of ulcer and type of ulcer in dogs presented at Veterinary Clinical Complex, AAU, Anand from March, 2019 to February, 2020. General clinical examination and detailed ophthalmic examination including neuro-ophthalmic examination, special diagnostic procedures like, Schirmer tear test, Fluorescein test and Slit lamp biomicroscopy. The incidence of corneal ulcer was recorded and analysed.

\section{Results and Discussion}

During the period of present clinical study, total of 5129 dogs were presented with several ailments at the Veterinary Clinical Complex, Veterinary College, AAU, Anand. Among them 4.28 percent $(n=220)$ dogs were found to be affected with various ocular affections and 0.64 percent $(n=33)$ dogs were diagnosed with corneal ulcer. Out of 220 cases of ocular affections, the highest cases of corneal melanosis $(25 \%, 55$ cases $)$, followed by corneal ulcer $(16.81 \%, 33$ cases) and cataract $(13.63 \%, 30$ cases $)$ were observed. Out of 33 cases (37 eyes) maximum superficial corneal ulcer was recorded (62.16 $\%, 23$ eyes) followed by Indolent ulcer (18.91\%, 7 eyes), Deep ulcer $(13.51 \%, 5$ eyes), Descemetocele $(5.40 \%, 2$ eyes). The agewise distribution of cases revealed maximum incidence of corneal ulcer 45.45 percent $(n=15)$ found in the age group of 0 to 3 years (Table 1) followed by 30.30 percent $(\mathrm{n}=10)$ incidence of 3 to6-year-old dog and 24.24 percent $(n=8)$ in $>6$ year which may have attributed to the playful nature of young one which make them more prone to traumatic injuries. The present findings are in accordance with the observation reported Goulle (2012), Ramani et al., (2013) and
Parulekar (2016), who also reported the highest incidence of corneal ulcer in 1 to 6year age group. The incidence of corneal ulcer was slightly more in male 51.51 percent (51.51\%, 17 dogs) than female $(48.48 \%, 16$ dogs) (Table 2). This finding is in accordance with the findings of Venugopal (2011), Goulle (2012), Ramani et al., (2013) and Parulekar (2016). Murphy et al., (2001) reported that there was no sex predilection seen in cases of corneal epithelial defects in dogs and also reported that dogs of any sex could be affected by corneal ulcer. During the period of present clinical study, in total of 33 dogs belonging to seven different breed were diagnosed with corneal ulcer. Among them breedwise maximum incidence was recorded in Pug dogs $(51.51 \%, 17$ dogs, 19 eyes) followed by Pomeranian $(15.15 \%, 5$ dogs, 6 eyes), Mongrels (12.12\%, 4 dogs, 4 eyes), Shih tzu (9.09\%, 3 dogs, 4 eye), Lhasa apso (3.03\%,1 dog, 1 eye), Bulldog (3.03\%, 1 dog, 2 eyes), Chow chow (3.03\%, 1 dog. 1 eyes) (Table 3) and Labrador (3.03\%, 1 dog, 1 eye). The over-representation of pug dogs with corneal ulcers may be because of lack many of the protective mechanisms operant in mesocephalic and dolichocephalic breeds (Barrett et al., 1991). The brachiochephalic nature causes excessive protrusion of the eyeballs and predisposes them to trauma. Brachycephalic breeds have characteristics features like lagophthalmos which predispose them to corneal injuries (Kim et al., 2009). Brachycepahlic dogs often have a thin lipid layer in the tear film and decreased aqueous coverage in the central cornea as a result of less blinking reflexes (Moore, 2003). Overrepresentation of pug dogs in this study could be attributed to their increased popularity as a pet (Chinchu, 2010). Out of 33 cases (37 eyes) of corneal ulcer four dogs $(12.12 \%)$ had bilateral corneal ulcer and $29 \operatorname{dogs}(87.87 \%)$ had unilateral corneal ulcer and corneal ulcer was found more in right eye $(59.45 \%, \mathrm{n}=22)$ than left eye (40.54\%, $\mathrm{n}=15)$.Among dogs 
$(n=33)$ studied for location of ulcer in eyes $(n=37)$, the highest incidence of ulcers located centrally (Table 4), followed by $21.62 \%$ $(n=8)$ dorso-nasal and $18.91 \%(n=7)$ ventronasal aspect. The higher percentage of centrally located ulcers might be due to exophthalmia, which prevents normal palpebral apposition and ultimately leads to uneven distribution of the tear film at central region of cornea. Dorbandt et al., (2015) recorded similar findings as of the present study with higher percentage of centrally located ulcer. Based on the history and clinical observation the most common cause of corneal ulcer was traumatic injury (62.16\%, $\mathrm{n}=23$ ), followed by keratoconjunctivitissicca (KCS) (27.02\%, $\mathrm{n}=10)$, entropion $(8.10 \%, \mathrm{n}=3)$ and chemical injury $(2.70 \%, \mathrm{n}=1)$ (Table 5). The inherent lower sensitivity of cornea in brachycephalic dogs breeds negatively affect the function of cornea protective mechanisms, which leads to traumatic injury to the cornea and allow the ulcers in the initial stages to go unnoticed by owners (Hakanson and Merideth, 1987). The results obtained in this study are in accordance with earlier studies of Mandell (2000) (Fig. 1-4).

Table.1 Agewise distribution of the dogs $(n=33)$ having corneal ulcer

\begin{tabular}{|c|c|c|}
\hline Age groups & No. of dogs & Percent \\
\hline < 1 year & 6 & 18.18 \\
\hline 1 year to 5 years & 19 & 57.58 \\
\hline > 5 year & 8 & 24.24 \\
\hline Total & 33 & 100.00 \\
\hline
\end{tabular}

Table.2 Sexwise distribution of the dogs $(n=33)$ having corneal ulcer

\begin{tabular}{|c|c|c|}
\hline Sex of dogs & No. of dogs & Percent \\
\hline Male & 17 & 51.51 \\
\hline Female & 16 & 48.49 \\
\hline Total & 33 & 100.00 \\
\hline
\end{tabular}

Table.3 Breedwise distribution of the dogs $(n=33)$ having corneal ulcer

\begin{tabular}{|c|c|c|}
\hline Breeds of dogs & No. of dogs & Percent \\
\hline Pug & 17 & 51.51 \\
\hline Pomeranian & 5 & 15.15 \\
\hline Mongrels & 4 & 12.13 \\
\hline Shih Tzu & 3 & 9.09 \\
\hline Lhasa Apso & 1 & 3.03 \\
\hline Bulldog & 1 & 3.03 \\
\hline Chow Chow & 1 & 3.03 \\
\hline Labrador Retriever & 1 & 3.03 \\
\hline Totoal & 33 & 100.00 \\
\hline
\end{tabular}


Table.4 Location wise distribution of dogs having corneal ulcer

\begin{tabular}{|c|c|c|}
\hline Location of Corneal ulcer & No. of eyes & Percent \\
\hline Central & 13 & 35.15 \\
\hline Dorsonasal & 8 & 21.62 \\
\hline Ventronasal & 7 & 18.91 \\
\hline Dorsotemporal & 5 & 13.51 \\
\hline Ventrotemporal & 4 & 10.81 \\
\hline Total & 37 & 100.00 \\
\hline
\end{tabular}

Table.5 Causative factors in the cases of corneal ulcers

\begin{tabular}{|c|c|c|}
\hline Causative factor & No. of eyes & Percent \\
\hline Traumatic injury & 23 & 62.16 \\
\hline Keratoconjunctivitissicca & 10 & 27.04 \\
\hline Entropion & 3 & 8.10 \\
\hline Chemical injury & 1 & 2.70 \\
\hline Totoal & 37 & 100.00 \\
\hline
\end{tabular}

Fig.1 Superficial corneal ulcer

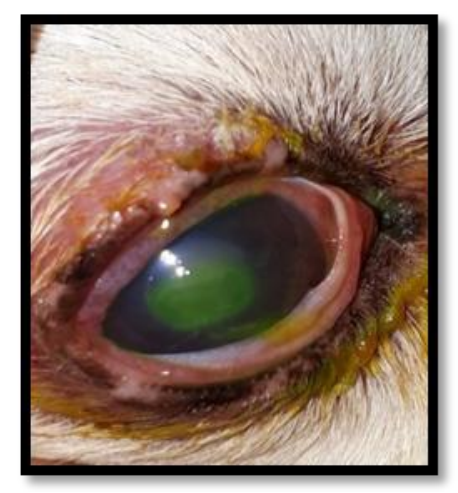

Fig.3 Indolent corneal ulcer

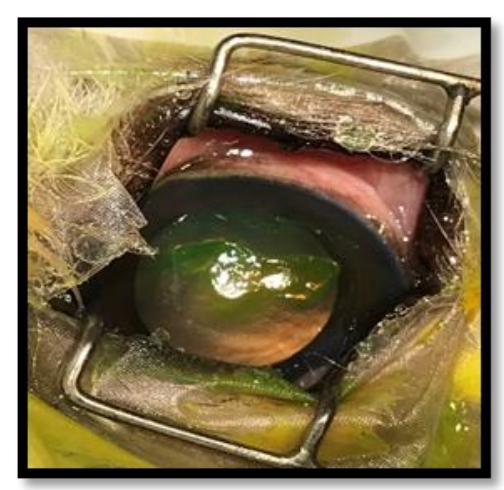

Fig.2 Deep corneal ulcer

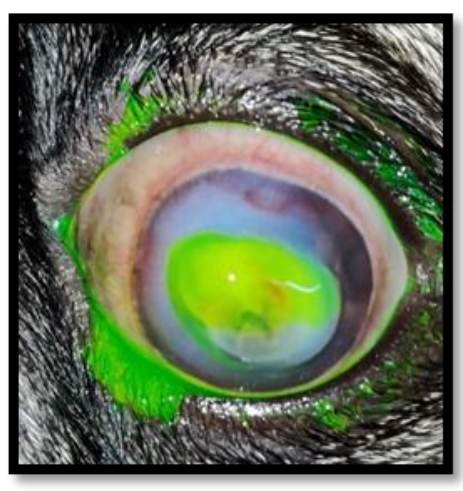

Fig.4 Descemetocele

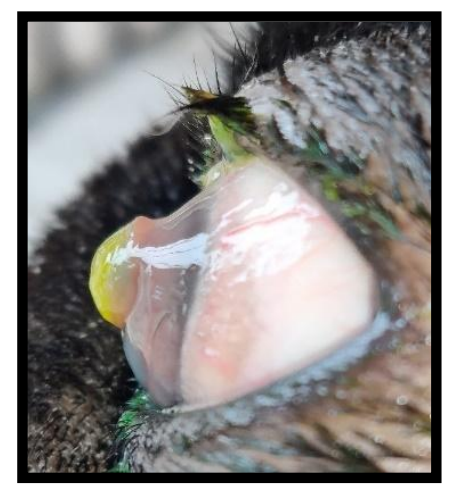


Based on the result of the present study, it can be concluded that Corneal ulcers are the common ophthalmic condition of young Pug dogs. Traumas followed by Keratoconjunctivitissicca were the common causes for the development of corneal ulceration in dogs.

\section{Acknowledgement}

The authors express profound of gratitude to the Dean, Collage of Veterinary Science and Animal Husbandary, Anand for the facilities provided. Senior author is thankful to major advisor and members of advisory committee for their constant guidance and help to carry out this research work smoothly.

\section{References}

Barrett, P. M., Scagliotti, R. H., Merideth, R. E., Jackson, P. A., and Alarcon, F. L. 1991. Absolute corneal sensitivity and corneal trigeminal nerve anatomy in normal dogs. Bull Terrier F, 1(25), 21.

Dorbandt, D. M., Moore, P. A., and Myrna, K. E. 2015. Outcome of conjunctival flap repair for corneal defects with and without an acellular submucosa implant in 73 canine eyes. Veterinary Ophthalmology, 18, 116-122.

Dutta, S. 2006. The eye: window to the world. Science Reporter, 4(5), 43.

Goulle, F. 2012. Use of porcine small intestinal submucosa for corneal reconstruction in dogs and cats: 106 cases. Journal of Small Animal Practices, 53, 34-43.

Hakanson,N. E., and Merideth, R .E. 1987. Conjuntival pedicle grafting in the treatment of corneal ulcers in the dog and cat. Journal of American Animal Hospital Association, 23, 641-648.

Kim, J. Y., Won, H. J., andJeong, S. W. 2009. A retrospective study of ulcerative keratitis in 32 Dogs. International
Journal of Applied Veterinary Research Medicine, 7(1), 27-31.

Mandell, D. C. 2000. Ophthalmic emergencies. Clinical Techniques in Small Animal Practice, 15(2), 94-100.

Moore, P. A. 2003. Diagnosis and management of chronic corneal epithelial defects (indolent corneal ulcerations). Clinical Techniques in Small Animal Practice, 18(3), 168-177.

Moore, P. A. 2003. Diagnosis and management of chronic corneal epithelial defects (indolent corneal ulcerations). Clinical Techniques in Small Animal Practice, 18(3), 168-177.

Murphy, C. J., Marfurt, C. F., McDermott, A., Bentley, E., Abrams,G .A., Reid, T. W., and Campbell. S. 2001. Spontaneous chronic corneal epithelial defects (SCCED) in dogs: Clinical features, innervation, and effect of topical SP, with or without IGF-1. Investigative Ophthalmology and Visual Science, 42, 2252-2261.

Parulekar, E. A. 2016. Studies on the Incidence, Diagnosis and Management ofDifferent Ocular Affections in Brachycephalic Dogs. Post graduate thesis submitted to Anand Agricultural University, Anand, Gujarat - 388 001, India.

Ramani, C., Rambabu, K., D’Souza, N. J., Vairamuthu, S., Subapriya, S., and William, B. J. 2013. Surgical bacteriology and grading of corneal ulcers in dogs a retrospective study in 24 dogs. Indian Journal of Canine Practice, 5(1), 136-138.

Slatter, D. 2001. Structure and function of the eye. In: Fundamentals of Veterinary Ophthalmology, (3 ${ }^{\text {rd }}$ ed., pp.1287-1304). W.B. Saunders Company, Philadelphia, London, New York, St. Louis, Sydney, Toronto.

Slatter, D. 2001. Structure and function of the eye. In: Fundamentals of Veterinary 
Ophthalmology, ( ${ }^{\text {rd }}$ ed., pp.1287-1304). W.B. Saunders Company, Philadelphia, London, New York, St. Louis, Sydney, Venugopal, C. S. 2011. Cause of corneal ulceration in Pugs. Indian Veterinary Journal, 12, 23-33.

Toronto.

\section{How to cite this article:}

Patel, K. P., P. V. Parikh, J. K. Mahla, S. N. Ashwath and Kelawala, D. N. 2020. Incidence of Corneal Ulcer in Dogs - A Retrospective Study. Int.J.Curr.Microbiol.App.Sci. 9(08): 31743179. doi: https://doi.org/10.20546/ijcmas.2020.908.361 